AperTO - Archivio Istituzionale Open Access dell'Università di Torino

\title{
Tax-limited reaction functions
}

\section{This is a pre print version of the following article:}

Original Citation:

Availability:

This version is available http://hdl.handle.net/2318/138487

since 2016-07-11T12:53:43Z

Published version:

DOI:10.1002/jae.1275

Terms of use:

Open Access

Anyone can freely access the full text of works made available as "Open Access". Works made available under a Creative Commons license can be used according to the terms and conditions of said license. Use of all other works requires consent of the right holder (author or publisher) if not exempted from copyright protection by the applicable law. 


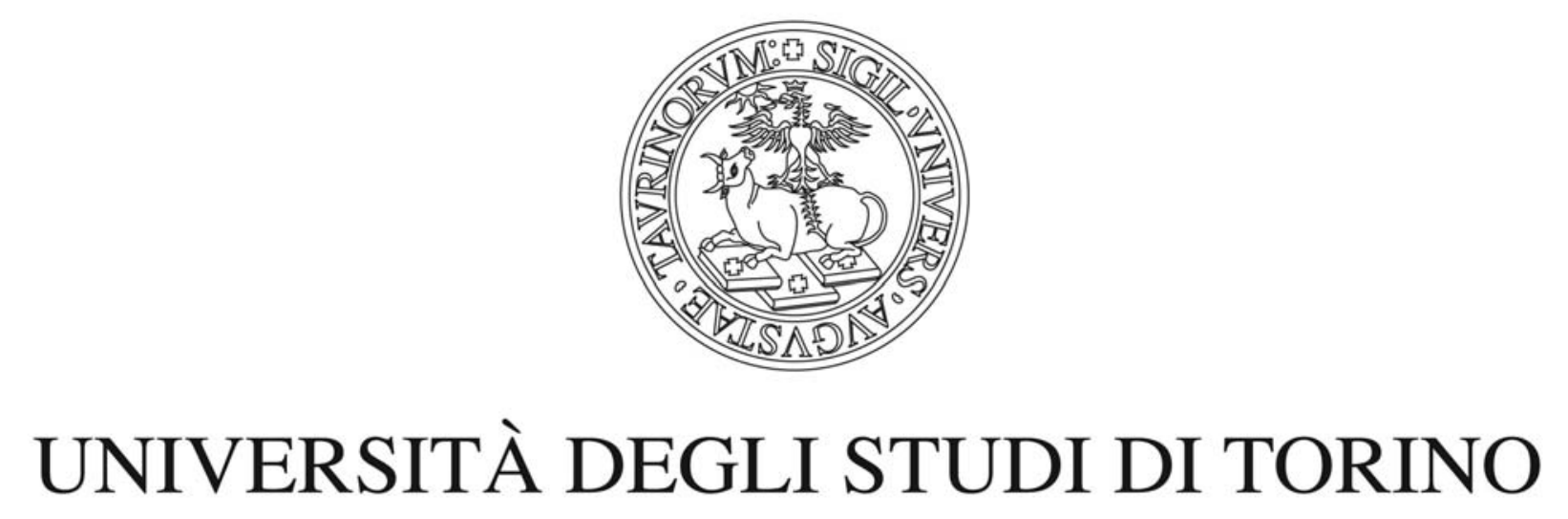

This is an author version of the contribution published in:

Questa è la versione dell'autore dell'opera pubblicata in:

Journal of Applied Econometrics, vol. 28(5), 2013, pp. 823-839

DOI: 10.1002/jae.1275

The definitive version is available at:

La versione definitiva è disponibile alla URL:

http://hdl.handle.net/10.1002/jae.1275 


\title{
Tax limited reaction functions
}

\author{
Edoardo Di Porto* $\quad$ Federico Revelli ${ }^{\dagger}$
}

July, 2010

\begin{abstract}
This paper explores for the first time the consequences of fiscal limitations on the estimation of local tax reaction functions. We focus on the frequently encountered case of local tax caps and compare four empirical approaches: 1) the spatial lag specification that does not account for corner solutions at the tax limits; 2) a Bayesian spatial approach for censored dependent variables; 3) a Tobit model augmented with a spatial lag; 4) a spatial discrete hazard model. The evidence arising from an investigation of severely state-constrained local vehicle taxes in Italy suggests that ignoring tax limitations can lead to substantial underestimation of inter-jurisdictional fiscal interaction.
\end{abstract}

JEL classification: C23; C24; H71.

Key words: tax limitations; tax reaction function; spatial auto-correlation.

${ }^{*}$ EQUIPPE, Université des Sciences et Technologies de Lille 1, Faculté des Sciences Economiques et Sociales, 59655 Villeneuve d'Ascq Cedex (France); e-mail: edoardo.diporto@univ-lille1.fr.

${ }^{\dagger}$ Corresponding author. Department of Economics, University of Torino, Via Po 53, 10124 Turin (Italy); e-mail: federico.revelli@unito.it. 


\section{Introduction}

The nature of central-local relationships in M-form (multi-divisional form) public sector structures plays a crucial role in determining the observed degree of tax and public expenditure decentralization and the actual extent of local fiscal autonomy (Maskin et al. [27]). As documented in Joumard and Kongsrud [20] and Sutherland et al. [37], most OECD country governments exercise their command by imposing lower and/or upper limits on local tax rates or by mandating types and levels of expenditures on local public services, and forty-six of the US states place restrictions on local property taxes (Calabrese and Epple [7]). ${ }^{1}$ Overall, the examples of local tax limitations around the world are countless. $^{2}$

The issue of mandating and capping on decentralized fiscal policies has attracted considerable interest in the theoretical and empirical public economics literature. Cremer and Palfrey [9] formally model the genesis of central mandates in federal systems, and Nechyba [29], Vigdor [39] and Calabrese and Epple [7] investigate origins and political support for tax limitations. Wang [40] and Konrad [22] discuss the consequences of minimum tax rates in theoretical models of commodity and capital income tax competition respectively, while most of the empirical literature concerns the impact of tax and expenditure limitations on policy outcomes in the US states (Figlio [14], Downes et al. [10], Dye et al. $[12])$.

On the other hand, little attention has been devoted to the investigation of the consequences of tax limitations on the empirical modelling of spatially dependent local fiscal policies. Somewhat surprisingly, while it has long been recognized that a key feature of decentralized fiscal policy-making is the interdependence among decision-makers due to a variety of fiscal externalities (Brueck-

\footnotetext{
${ }^{1}$ Local property tax rate limitations in the US states date back as early as the 1930s, and became widespread after California's Proposition 13 in the late 1970s (Wolman et al. [41]).

${ }^{2}$ Local tax limitations are in place in virtually all European countries, most frequently including local property taxes (for instance, the Impuesto sobre los bienes inmuebles in Spain and the Grundsteuer in Germany) and local business taxes (as the Taxe professionelle in France and the Imposta regionale sulle attività produttive in Italy).
} 
ner [5]), all of the existing empirical analyses of inter-jurisdictional competition rest on the often implausible assumption that local decision-makers are actually free to choose their preferred policies. In fact, in an early study of property tax competition within the Boston metropolitan area, Brueckner and Saavedra [6] highlighted the link between local tax limitations and the intensity of tax competition. They pointed out that "reaction functions become flat once they encounter the levy-limit constraint" (Brueckner and Saavedra [6], p. 220), and acknowledged that "implementing this kind of double regime specification in a spatial lag context appears difficult" (Brueckner and Saavedra [6], p. 220). Focusing on the regime switch represented by the introduction of the local tax limitation known as Proposition $2 \frac{1}{2}$, they found that the degree of spatial autocorrelation in local property taxes was somewhat lower in the presence of the tax cap.

This paper attempts at exploring for the first time the consequences of the existence of tax limits on the modelling and estimation of a local fiscal policy reaction function. In particular, we compare four empirical approaches to the analysis of spatial auto-correlation in local tax policies: 1) the conventional spatial lag specification that does not account for corner solutions at the tax limits; 2) a Bayesian spatial approach for censored dependent variables; 3) a Tobit model augmented with a spatial lag; 4) a spatial discrete hazard model focusing on the discrete corner solution outcome.

While in general, and similarly to standard multivariate analysis of limited dependent variables, the direction and size of the bias arising from ignoring tax limitations are unknown a priori (Pudney [33]), the Brueckner and Saavedra [6] intuition suggests that tax reaction functions become flat once authorities hit the tax limit, thereby leading to underestimation of the degree of interjurisdictional fiscal interaction when overlooking the constraint-induced corner solutions.

In order to verify if that intuition is correct and evaluate the performance of the above empirical approaches, we apply them to panel data over the years 
2000 to 2006 on the vehicle registration tax policies of the one-hundred Italian provinces, where the state-wide tax rate cap was binding for about half of the authorities in the year 2000 and up to almost $90 \%$ of them in the year 2006 . While almost entirely neglected in the empirical public economics literature, vehicle taxation is widely employed at the decentralized level in both developed and developing countries, and might generate spatial auto-correlation for two reasons. ${ }^{3}$ First, as long as the tax base (motor vehicles) is mobile across jurisdictions, local vehicle taxation might give rise to tax competition to attract tax base and induce correlation across neighboring authorities' policies. Second, due to the high visibility of vehicle taxes and the widespread ownership of motor vehicles, vehicle taxation can work as a signal of a government's quality, and could therefore foster accountability and yardstick competition between decentralized governments (Besley and Case [4]).

The evidence from the Italian provinces' vehicle tax data suggests that ignoring tax limitations can lead to substantial underestimation of inter-jurisdictional fiscal interaction. Explicitly allowing for the corner solutions generated by tax limitations unveils a significantly stronger process of spatial interaction: the Tobit model yields an estimate of the spatial auto-regressive coefficient that is about twice as large as either the standard maximum likelihood estimate that ignores tax limits or the Bayesian spatial censored model one, and the discrete hazard model provides further evidence that the probability of an authority hitting the upper censoring point is strongly affected by the fiscal choices of neighboring authorities. These results call for a thorough rethinking of the existing empirical evidence on spatial auto-correlation in local tax policies.

The paper devotes the next four sections to the illustration of each of the estimation approaches in turn. Section 6 turns to their application to the Italian provinces' vehicle taxes, and section 7 concludes.

\footnotetext{
${ }^{3}$ Empirical analyses of decentralized vehicle taxation are Mahadi et al. [25], Suter and Walter [38] and Solé Ollé [36].
} 


\section{The spatial lag dependence model}

Local governments around the world are frequently subject to stringent regulations on their tax and spending decisions, making the ideal paradigm of intergovernmental competition sort of blurred in practice. A frequently encountered case is a cap $(\bar{\tau})$ on a local tax rate $\tau$, meaning that $\tau \leq \bar{\tau}$ and ideally calling for a corner solution model accounting for clustering at the tax limit.

Scholars applying spatial econometric techniques to local government data have typically ignored those tax limitations and modelled the tax reaction function as a spatial lag specification that takes the vector of observed local tax policies as the continuous dependent variable: ${ }^{4}$

$$
\tau_{i t}=\rho \tau_{-i t}+x_{i t}^{\prime} \beta+\varepsilon_{i t}
$$

where $\tau_{i t}$ is the tax rate set by jurisdiction $i(i=1, \ldots, N)$ in year $t(t=$ $1, \ldots, T$ ), and $\rho$ (with $-1<\rho<1$ to ensure spatial stationarity) is the firstorder spatial auto-regressive coefficient relating own tax rates to the spatially weighted average of other jurisdictions' tax rates:

$$
\tau_{-i t}=\sum_{j=1}^{N} w_{i j} \tau_{j t}
$$

where $w_{i j}$ are non-stochastic weights that formalize the arrangement of jurisdictions in space. For instance, according to the conventional binary contiguity criterion and upon row-normalization, $w_{i j}$ equals $\frac{1}{n_{i}}$ if jurisdiction $j$ is adjacent to jurisdiction $i$, and equal 0 otherwise, with $n_{i}$ being the number of units sharing a border with unit $i .^{5}$ Finally, $\varepsilon_{i t}$ is assumed to be independently and identically distributed across geographical units and over time. ${ }^{6}$

\footnotetext{
${ }^{4}$ See the reviews in Brueckner [5], Allers and Elhorst [1] and Revelli [34]. More recent work (Elhorst [13]) calls for more general and encompassing spatial specifications, that nonetheless ignore the external constraints on local government policies.

${ }^{5}$ Clearly, alternative weighting criteria might be employed in order to reflect possibly more involved - and not necessarily of a geographical nature - interaction processes among local units (Revelli [34], [35]). However, the adoption of an adjacency-based criterion should suffice for the point to be made in this paper, and can be easily extended to any weighting criterion.

${ }^{6}$ In fact, residual spatial autocorrelation, i.e., the possibility of a spatial process in $\varepsilon_{i t}$, ought to be tested for before estimating the spatial lag specification (1). See Elhorst [13] and section 6 below.
} 
The spatial lag dependence model can be inverted and expressed in matrix form as:

$$
\tau=(I-\rho W)^{-1} X \beta+(I-\rho W)^{-1} \varepsilon
$$

where $I$ is the $(N T \times N T)$ identity matrix and $W=\left[I_{T} \otimes W_{N}\right]$ is the blockdiagonal, row-standardized spatial weights matrix, with $W_{N}=\left\{w_{i j}\right\}, i, j=$ $1, \ldots, N$, and $\sum_{j} w_{i j}=1, \forall i$. Formulation (3) makes it clear that, with $\rho \neq 0$, a perturbation at any location will be transmitted to all other units. By assuming that $\varepsilon_{i t} \sim N\left(0, \sigma_{\varepsilon}^{2}\right)$, (3) can conveniently be estimated by standard maximum likelihood (ML) techniques (Anselin [2]).

Suppose now that central government imposes the tax limitation $\tau_{i t} \leq \bar{\tau}$, generating an additional constraint on local government choices, with a positive probability that local government $i$ is at a corner solution outcome in period $t: \tau_{i t}=\bar{\tau}$. Overlooking the fact that a number of authorities might be taxconstrained at $\bar{\tau}$ is bound to lead to similar problems as the ones that are encountered in non-spatial econometric settings when the dependent variable is limited (Pudney [33]). In particular, and most importantly for our purposes, the maximum likelihood estimate of the first-order spatial auto-regressive coefficient $\rho$ measuring the slope of the reaction function (1) is biased. Intuitively, when an authority hits the tax limit, its reaction function becomes flat $(\rho=0)$, giving the impression of deliberately setting its tax policy independently of other jurisdictions, while being in reality constrained by state limitations to do so.

\section{A Bayesian censored dependent variable ap- proach}

One possibility of empirically modelling a spatial process as (1)-(2) while allowing for the tax limitation $\tau_{i t} \leq \bar{\tau}$ consists in "estimating" in a Bayesian fashion the tax rates that would be observed in the absence of tax limitations (LeSage and Kelley Pace [24]). Calling $\tau_{i t}^{*}$ the "desired" tax rate by authority $i$ in year $t$ - i.e., the tax rate that would be set in the absence of tax limitations, but that 
might be unobserved due to capping - the ultimate objective of the empirical analysis turns out to consist in recovering the "true" slope parameter $\rho$ in a reaction function where desired tax rates are spatially auto-correlated: ${ }^{7}$

$$
\begin{gathered}
\tau_{i t}^{*}=\rho \tau_{-i t}^{*}+x_{i t}^{\prime} \beta+\varepsilon_{i t} \\
\tau_{-i t}^{*}=\sum_{j=1}^{N} w_{i j} \tau_{j t}^{*}
\end{gathered}
$$

with $w_{i j}$ being defined as in (2) above, and the observed tax rate being generated as:

$$
\tau_{i t}=\left\{\begin{array}{ccc}
\bar{\tau} & \text { if } & \tau_{i t}^{*} \geq \bar{\tau} \\
\tau_{i t}^{*} & & \tau_{i t}^{*}<\bar{\tau}
\end{array}\right.
$$

In a way, model (1)-(2) is the observed, tax limited counterpart of the latent model (4)-(5). However, by positing that spatial auto-correlation in observed fiscal policies is originated from dependence in the latent variable $\tau^{*}$, the specification (4)-(5) has a not-so-intuitive implication: since both the own tax $\left(\tau_{i t}\right)$ and the taxes in neighboring jurisdictions $\left(\tau_{-i t}\right)$ are only observed after capping, the direction and size of the bias deriving from estimation of model (1)-(2) instead of the true but unobserved process (4)-(5) are unknown a priori.

With $-1<\rho<1$, the matrix form of equation (4) can be inverted and expressed as:

$$
\tau^{*}=(I-\rho W)^{-1} X \beta+(I-\rho W)^{-1} \varepsilon
$$

with variance-covariance matrix:

$$
\Omega=(I-\rho W)^{-1}(I-\rho W)^{-1 \prime} \sigma_{\varepsilon}^{2}
$$

The substantial difference of the latent variable model (7) with respect to a non-spatial specification $(\rho=0)$ is that the spatially correlated covariance structure (8) does not allow the simplification of the multivariate distribution into the product of univariate distributions. Moreover, the heteroscedasticity

\footnotetext{
${ }^{7}$ The argument that is being made here relies on the assumption that observations below the censoring point are unaffected by the existence of the tax cap. However, Konrad [22] shows that this might not be the case in a theoretical framework of Stackelberg competition for mobile capital, due to the strategic effect of a non-binding tax limit.
} 
implied by the spatial covariance structure causes inconsistency of standard nonspatial limited dependent variable estimation methods (McMillen, [28]; Fleming $[16])$.

A number of approaches have been recently proposed to consistently estimate variants of model (7), particularly with reference to a binary dependent variable setting (spatial Probit), and where spatial dependence typically takes the form of a first-order autoregressive process in the residuals (Pinkse and Slade [32]):

$$
\begin{aligned}
\tau^{*} & =X \beta+v \\
v & =\lambda W v+\varepsilon \\
\varepsilon & \sim N(0, I)
\end{aligned}
$$

where $\lambda$ (with $-1<\lambda<1$ ) is the auto-regressive coefficient in the spatial error process and $W$ is as defined above. ${ }^{8}$

The proposed estimation methods for the above models either focus on the heteroscedasticity induced by the spatial model structure and address it by making specific assumptions on the form of the spatial weights matrix (Case [8]) and the variance-covariance structure (Pinkse and Slade [32]), or make full use of the spatial information and rely on computationally complex techniques (the EM algorithm, simulation methods or Bayesian methods) to tackle the issue of multidimensional integration (Fleming $[16]) .^{9}$

Within the latter class of models, the Bayesian spatial discrete choice method developed by LeSage [23] overcomes some drawbacks that arise in the EM algorithm when estimating standard errors (McMillen [28]), and has the advantage of allowing the errors to be heteroscedastic after controlling for spatial dependence. Moreover, it tends to be superior to simulation methods (Beron and Vijverberg [3]) in terms of computational requirements and flexibility (Fleming [16]). Most importantly, though, the LeSage Bayesian approach is the best

\footnotetext{
${ }^{8}$ Flores-Lagunes and Schnier [17] develop a sample selection model with spatial error dependence both in the selection and in the main equation.

${ }^{9}$ Klier and McMillen [21] propose a linearized logit version of Pinkse and Slade [32] spatial GMM estimator that can be applied to a model with a spatially lagged latent dependent variable.
} 
suited to estimate a censored dependent variable model with simultaneous spatial dependence as in (7) above.

The Bayesian spatial approach is based on the principle that a likelihood function for model (7) can be formulated and optimized based on "estimates" of the unobserved latent variable $\tau^{*} \cdot{ }^{10}$ In practice, the approach relies on the actual observed $\tau$ values for uncensored observations, while estimates of the unobserved latent variables $\tau^{*}$ for censored observations are obtained through Gibbs sampling from a distribution of the latent variable (truncated at $\bar{\tau}$ ) conditional on all other parameters in the model. ${ }^{11}$

The idea underlying the Bayesian spatial approach is similar to the EM algorithm proposed by McMillen [28], where the censored or latent unobserved observations on the dependent variable are replaced by estimated values. Given estimates of the missing values, the EM algorithm proceeds to estimate the other parameters in the model using methods applied to non-truncated data samples. In other words, conditional on the estimated values, the estimation problem is reduced to a non-censored estimation problem that can be solved using maximum likelihood methods. Similarly, once a sample for the unobserved latent dependent variables has been generated via the Gibbs sampler, the problem reduces to a Bayesian heteroscedastic spatial auto-regressive model. Moreover, the Bayesian spatial procedure yields the mean and dispersion of all parameters, including the crucial spatial lag coefficient $\rho$.

\section{A Tobit approach}

A potential drawback of the spatial latent variable specification (4)-(5) consists in the fact that it best applies to instances of true censoring - i.e., nonobservability of a variable above a given threshold, - while it is unlikely to

\footnotetext{
${ }^{10}$ The LeSage [23] approach is extensively discussed in Fleming [16] and LeSage and Kelley Pace [24]. The LeSage procedure has recently been applied to a local public finance context by Fiva and Rattso [15].

${ }^{11}$ The Gibbs sampler is an algorithm able to generate a sequence of samples from a joint probability distribution of two (or more) random variables. It can be shown that the sequence of samples constitutes a Markov chain, and the stationary distribution of that Markov chain is just the sought-after joint distribution (LeSage and Kelley Pace [24]).
} 
capture the competition process that is at work in typical local public finance contexts, where tax limitations produce corner solution outcomes. In the presence either of yardstick or tax competition, each jurisdiction should be supposed to care about the actual policies enacted by its neighbors, not their (unobserved) desired ones. As a result, the empirical specification would require the "ideal" tax policy of each government $\left(\tau_{i t}^{*}\right)$ to be affected by neighboring jurisdictions' observed tax policies $\left(\tau_{j t} ; j \neq i\right)$.

Unfortunately, though, a simultaneous dependence model where desired policies $\tau^{*}$ are allowed to depend on neighbors' contemporaneous policies is known to be algebraically inconsistent and cannot therefore be implemented empirically (Beron and Vijverberg [3]). As a result, a reasonable way to move forward consists in following here the spatial discrete choice approach developed by Dubin [11] and implemented, among the others, by Hautsch and Klotz [18], Paez and Scott [30] and Paez et al. [30], and allowing own attitudes towards taxation $\left(\tau_{t}^{*}\right)$ to be affected by neighbors' lagged fiscal policies $\left(\tau_{j t-1} ; j \neq i\right)$. This implies modelling the latent tax policy as:

$$
\tau_{i t}^{*}=x_{i t}^{\prime} \beta+\rho \tau_{-i t-1}+\varepsilon_{i t}=x_{i t}^{\prime} \beta+\rho \sum_{j=1}^{N} w_{i j} \tau_{j t-1}+\varepsilon_{i t}
$$

Besides depicting a realistic process by which corner solutions arise as outcomes of fiscal externalities generated by the actual policies implemented in nearby localities, specification (12) can also be justified by the idea that the adjustment to neighboring authorities' policies does not take place instantly due to the sluggishness of the political process. Neighboring jurisdictions' tax policies at time $t-1$ affect an authority's tax policy at time $t$ and, in the presence of the tax limitation $\tau_{i t} \leq \bar{\tau}$, authority $i$ might end up in a corner solution outcome if $\tau_{i t}^{*}>\bar{\tau}$

Therefore, assuming a normal distribution for the error term in (12), a corner solution Tobit model can be estimated, with:

$$
\tau_{i t}=\left\{\begin{array}{ccc}
\bar{\tau} & & \tau_{i t}^{*} \geq \bar{\tau} \\
\tau_{i t}^{*} & \text { if } & \tau_{i t}^{*}<\bar{\tau}
\end{array}\right.
$$


In particular, in order to obtain an estimate of the degree of inter-jurisdictional interaction that is comparable with the maximum likelihood estimate of the spatial lag dependence model that ignores the tax limitations, we will focus on the marginal effects based on the expected value of the tax rate conditional on exogenous observable variables and neighbors' tax rates $\left(E\left(\tau_{i t} \mid x_{i t}, \tau_{-i t-1}\right)\right)$ and on the expected value of the tax rate for the subsample of unconstrained authorities $\left(E\left(\tau_{i t} \mid \tau_{i t}<\bar{\tau}, x_{i t}, \tau_{-i t-1}\right)\right)$.

\section{A discrete hazard approach}

Finally, the spatial latent variable specification (4)-(5) relies on the assumption that, in every period, a government elaborates its optimal tax rate based on the realizations of the observables. However, it is rarely the case in practice that a government hitting the upper bound (the tax cap) ever reverts from there in the future. ${ }^{12}$ As a result, it might be sensible to treat the occurrence of a government hitting the upper bound as a discrete and irreversible event. In order to do so, we model the event of local government $i$ hitting the threshold $\tau_{i t}=\bar{\tau}$ at some point $t=1, \ldots, T$ as a failure, and estimate the probability or hazard - of exiting from the inner interval $(0, \bar{\tau})$ in period $t$ conditional on having survived until then (Jenkins [19]).

In particular, let $T_{i} \in t=\{1,2, \ldots, T\}$ denote the discrete survival time of local government $i$, i.e., the number of years that elapse before the government sets the maximum tax rate. The authorities surviving until the end of the period with $\tau_{i t}<\bar{\tau}$ have a (censored) duration of $T_{i}=T$. The hazard function of $T_{i}$ is the probability that $T_{i}=t$, conditional on government $i$ not having failed in previous periods and on a number of time-varying characteristics - the vector $x_{i t}$ discussed with reference to the reaction function (1) - plus a set of time dummies capturing duration dependence. By choosing a normal distribution for the formulation of the probability of exit, we can estimate a Probit model where the dependent variable is binary: $y_{i t} \in\{0,1\}$. Observations for which

\footnotetext{
${ }^{12}$ See section 6 below for evidence in this respect.
} 
the event never occurs in the period considered take value 0 in all years; when the event occurs $\left(y_{i t}=1\right)$, the local government exits the sample:

$$
y_{i t}=\left\{\begin{array}{lll}
1 & \text { if } & \tau_{i t}^{*} \geq \bar{\tau} \\
0 & & \tau_{i t}^{*}<\bar{\tau}
\end{array}\right.
$$

In order to ascertain whether neighboring governments' fiscal choices affect the probability that a government hits the upper bound, we allow $\tau_{i t}^{*}$ to be defined as in (12) above. As a result, the lagged choices of neighboring jurisdictions can be treated as exogenous, and the hazard model can be estimated by standard Probit. Clearly, being the dependent variable a binary one in (14), the estimated coefficients from the discrete hazard model - in particular, the change in probability of hitting the tax limit following a change in the $\tau_{j t-1}$ variable will only be qualitatively comparable with the ones from the previous models.

\section{The provincial vehicle tax in Italy}

The Italian system of local government is organized as a three-tier structure, with over 8,000 municipalities, 100 provinces and 20 regions. ${ }^{13}$ Provinces play an important role in planning and coordinating municipal policies, particularly as far as the decisions that transcend strictly municipal boundaries - such as the control of industrial, car and heating pollution, as well as the management and disposal of waste - are concerned. Moreover, they have exclusive responsibility for the maintenance of intermunicipal roads, local transportation systems and secondary education schools.

Provincial authorities fund their expenditures through grants from upper levels of government and own tax revenues, that are mainly constituted (60\%) by the provincial vehicle registration tax. The provincial vehicle registration tax was introduced in the year 2000 in order to reduce reliance on external funding and to foster the accountability of administrations to their electorates. All motor vehicles are liable to the payment of the tax the first time they are

\footnotetext{
${ }^{13}$ There also exist three "autonomous" Provinces in the upper North mountaneous bilingual regions, with special features and competencies. Due to their peculiarities, they are not considered in the rest of the analysis.
} 
registered in the provincial archive under a given owner's name. The total tax due is made of a lump-sum amount plus a variable component that is related to the size, power and destination of the vehicle. Central government establishes a lower and an upper bound on the vehicle tax parameters, with the upper bound corresponding to a $20 \%$ higher tax burden than the one corresponding to the lower bound. Consequently, the decision of each province basically consists in determining autonomously the percentage tax spread ( $\tau$ from here onwards, with $0 \leq \tau \leq 20$ ).

Table 1 reports the average $\tau$ along with the number of provinces setting the minimum $(\tau=\underline{\tau}=0)$ and maximum $(\tau=\bar{\tau}=20)$ tax spreads in each of the seven years following its introduction (2000-2006). The table shows that provinces steadily raised their tax spreads over time, with almost $90 \%$ of them hitting the upper bound by the year 2006. ${ }^{14}$ A similar picture emerges from figure 1, where the evolution of the geographical pattern of the vehicle tax during the period under examination is depicted.

On the other hand, table 2 shows that the tax spread was raised by provincial governments 113 times. Interestingly, the last column in table 2 shows that in only four of the 113 instances the tax rise occurred in a year when a provincial election was scheduled to take place, with the remaining 109 tax rises being decided in safer non-election years. ${ }^{15}$ Furthermore, while the chances of success of the incumbent in the overall sample exceed $75 \%$, only $50 \%$ of the incumbents that raised the tax in election years managed to be re-elected, suggesting that electoral considerations play a role in vehicle tax setting, with provincial governments seeming to time tax increases in order to minimize their adverse popularity consequences. ${ }^{16}$

\footnotetext{
${ }^{14}$ Starting from 2007 , the cap was raised to $30 \%$.

${ }^{15}$ Provincial elections take place every five years, with direct popular election of the president of the Province, typically out of four to five candidates, and the members of the provincial Council. $\frac{3}{4}$ of the 100 Provinces held an election around the middle of the period (2003-2004), while some Provinces had an election in the early 2000s and went again to the polls five years later.

${ }^{16}$ This evidence must of course be taken with caution due to the very few occurrences of tax rises in election years. In fact, the small number of observations precludes us from explicitly estimating a re-election equation.
} 
In order to verify if vehicle taxes across adjacent provinces are correlated, we start from the estimation of the spatial lag specification (1) that ignores statewide tax limits. The vector of time-varying explanatory variables $x_{i t}$ includes grants per capita, income (value added) per capita, the stock of vehicles registered in the province in the previous year, a dummy that equals 1 in election years, a dummy that equals 1 if the government is right-wing, and the weighted average of neighboring provinces' tax spreads defined in equation (2). Based on the fact that the $(700 \times 1)$ vector of average neighboring provinces' tax spreads equals $[I \otimes W] \tau$, where $I$ is the $(7 \times 7)$ identity matrix and $W=\left\{w_{i j}\right\}$ is the $(100 \times 100)$ exogenous spatial weights matrix, the matrix form of equation (1) can be inverted as in (3) and estimated by maximum likelihood techniques. ${ }^{17}$

The results of estimation of a parsimonious specification that includes no control variables $(\beta=0)$ are reported in table 3 , while table 4 reports the results with all of the above explanatory variables included. Both specifications include fixed province $\left(q_{i}\right)$ and time $\left(z_{t}\right)$ effects. In tables 3 and 4 , the first column reports the results of OLS estimation of a non-spatial specification $(\rho=0)$; the second column reports the OLS estimates of the spatial lag specification; the third column shows the corresponding ML results; finally, the fourth column contains the ML estimation results of a spatial error dependence model (Anselin [2]), where $\rho=0$ and nearby provinces are allowed to be hit by spatially autocorrelated shocks:

$$
\begin{aligned}
\tau_{i t} & =x_{i t}^{\prime} \beta+q_{i}+z_{t}+v_{i t} \\
v_{i t} & =\lambda v_{-i t}+\varepsilon_{i t}
\end{aligned}
$$

where, similarly to equation $(2), v_{-i t}$ is defined as:

$$
v_{-i t}=\sum_{j=1}^{100} w_{i j} v_{j t}
$$

The tests for spatial auto-correlation in column (a) of table 3 and column (e) of table 4 point rather consistently towards positive spatial auto-correlation

\footnotetext{
${ }^{17}$ The likelihood function is maximized via the MAXLIK procedure in GAUSS.
} 
in the residuals of a non-spatial specification. ${ }^{18}$ In the fully specified equation, the LM (Lagrange Multiplier) tests tend to favour the spatial lag dependence model over the spatial error dependence one. ${ }^{19}$

The parsimonious specification in table 3 yields an OLS estimate of the spatial auto-correlation coefficient $\rho$ of about 0.20 , and an ML estimate of 0.12 . After controlling for a number of exogenous local characteristics (table 4), evidence of spatial dependence in $\tau$ dwindles. While the (upward biased) OLS estimate of $\rho$ in column (f) is 0.135 , the ML estimate of $\rho$ in column (g) of table 4 is an admittedly not overwhelming and only marginally significant value of 0.08 , pointing towards a pretty flat reaction function. However, as argued above, this is what one could expect given the tax limitation on the dependent variable, and $\widehat{\rho}_{M L}$ might be suffering from a downward bias. As for the other variables, right-wing ideology, proximity to elections, per capita income and grants from upper levels of government all tend to be associated with lower tax rates, and the stock of vehicles circulating in the province has a positive effect on the provincial tax rate.

Table 5, columns (i) and (j), reports the estimation results of the Bayesian spatial model. ${ }^{20}$ The estimate of the spatial auto-correlation coefficient is 0.15 and is highly significant in the basic specification with $\beta=0$, while it is around 0.10 when the effect of the explanatory variables is accounted for. Overall, the results from the Bayesian spatial model based on (4)-(5) provide a very similar picture as the spatial lag specification that ignores censoring. Moreover, the coefficient estimates on the other explanatory variables are similar in the two models.

Table 6 reports the corner solution Tobit and discrete hazard estimates.

\footnotetext{
${ }^{18}$ The Moran test is asymptotycally distributed as a standard normal under the null hypothesis of absence of spatial auto-correlation, while the LM tests against the hypotheses of a spatial lag - model (1) - or a spatial error - model (15)-(16) - are both distributed as $\chi^{2}(1)$ (Anselin [2]). All tests are performed in GAUSS.

${ }^{19}$ Clearly, the two LM tests take on the same value in table 3 , where no exogenous variables are included, since the spatial lag and spatial error models are indistinguishable in that case, as shown by the ML estimation results in columns (c) and (d).

${ }^{20}$ Estimation is performed in Matlab based on the routines for a spatial auto-regressive censored dependent variable model (sart_g function) provided by James LeSage (www.spatialeconometrics.com).
} 
Column (k) in table 6 reports the Tobit partial effects computed at the sample mean $E\left(\tau_{i t} \mid x_{i t}, \tau_{-i t-1}\right)$. Strikingly, the estimate of the effect of neighbors' tax rates on the own tax rate is almost twice as large as the ML estimate of $\rho$ and it is highly significant, and it is even higher in column (1), when the partial effect $\frac{\partial E\left(\tau_{i t} \mid \tau_{i t}<\bar{r}, x_{i t}, \tau_{-i t-1}\right)}{\partial \tau_{-i t-1}}$ is computed conditional on $\tau_{i t}<\bar{\tau}$, suggesting that ignoring the corner solutions generated by tax limitations might lead to substantial underestimation of the local interaction process.

Finally, column (m) in table 6 reports the discrete hazard model results. Since the 2000 cross-section is lost in taking the lag of neighboring provinces' tax rates and due to the fact that provinces leave the sample when hitting the upper bound, estimation is performed on an unbalanced panel data set of 150 observations, 32 of which reach the $\bar{\tau}$ limit over the years 2001 to 2006 .

Reported coefficients are partial probability effects computed at the sample means. Partial effects for dummy variables are computed as the change in probability when a dummy variable shifts from 0 to 1 , so that, for instance, the probability that a right-wing government hits the upper threshold is over ten percentage points lower than it is for a left-wing government. The coefficient on the election year dummy has a similar size, but it is not statistically significant, and there is no significant evidence of duration dependence.

As far as the effect of lagged neighboring provinces' tax policies is concerned, an increase by 2 percentage points in the average tax rate of neighboring provinces is estimated to raise the probability of a province hitting the upper bound $\bar{\tau}$ in the subsequent year by around 3 percentage points. This means that, for instance, an "average" left-wing government elected in year 2000 has an around $20 \%$ probability of hitting the tax limit in 2001 (the second year in the sample) if neighboring authorities were setting a zero tax spread in 2000 $\left(\sum_{j=1}^{N} w_{i j} \tau_{j t-1}=0\right)$, while the probability jumps to about $50 \%$ if all adjacent provinces were capped in year $2000\left(\sum_{j=1}^{N} w_{i j} \tau_{j t-1}=20\right)$. 


\section{Concluding remarks}

The empirical tax and yardstick competition literature that has grown impressively in the past two decades relies on the implicit and universal assumption that decentralized governments are free to set their tax policy instruments. However, local governments around the globe are hardly ever able to implement the policies they deem fit. In most instances, they are constrained by central government mandates on public expenditures or caps on local taxes.

This paper has explored for the first time the consequences of central capping on the modelling and estimation of a local fiscal policy reaction function. By means of an empirical application to provincial vehicle taxation in Italy, we have employed four empirical approaches to the estimation of the inter-jurisdictional spatial interaction coefficient in the frequently encountered case of central government exercising its command by imposing upper limits on local fiscal choices.

It turns out that explicitly allowing for the corner solutions generated by tax limitations unveils a significantly stronger process of spatial interaction than when employing conventional approaches: the Tobit model yields an estimate of the spatial auto-regressive coefficient that is around twice as large as either the standard maximum likelihood estimate that ignores tax limits or the Bayesian spatial censored model one, and the discrete hazard model provides further evidence that the probability of an authority hitting the upper censoring point is strongly and significantly affected by the fiscal choices of neighboring authorities.

While this paper represents just the first, tentative step into the investigation of the impact of top-down tax limitations on horizontal tax competition, and the evidence presented here should be taken as no more than illustrative, explicit recognition of the fact that local governments are "creatures of state governments" (Calabrese and Epple [7]) seems to call for a thorough rethinking of the existing empirical evidence on strategic interaction in local fiscal policies. 


\section{References}

[1] Allers, M., Elhorst, P., Tax mimicking and yardstick competition among local governments in the Netherlands, International Tax and Public Finance 12 (2005) 493-513.

[2] Anselin, L., Spatial Econometrics: Methods and Models, Kluwer Academic, Dordrecht, 1988.

[3] Beron, K., Vijverberg, W., Probit in a spatial context: A Monte Carlo analysis, in L. Anselin, R. Florax and S. Rey (eds), Advances in Spatial Econometrics, Springer, Heidelberg, 2004, pp. 169-195

[4] Besley, T., Case, A., Incumbent behavior: Vote seeking, tax setting and yardstick competition, American Economic Review 85 (1995) 25-45.

[5] Brueckner, J., Strategic interaction among governments: An overview of empirical studies, International Regional Science Review 26 (2003) 175-188.

[6] Brueckner, J., Saavedra, L., Do local governments engage in strategic property tax competition? National Tax Journal 54 (2001) 203-229.

[7] Calabrese, S., Epple, D., On the political economy of tax limits, Document de Treball \#14, Institut d'Economia de Barcelona (2010).

[8] Case, A., Neighborhood influence and technological change, Regional Science and Urban Economics 22 (1992) 491-508.

[9] Cremer, J., Palfrey, T., Federal mandates by popular demand, Journal of Political Economy 108 (2000) 904-927.

[10] Downes, T., Dye, R., McGuire, T., Do limits matter? Evidence on the effects of tax limitations on student performance, Journal of Urban Economics, 43 (1998) 401-417.

[11] Dubin, R., Estimating Logit models with spatial dependence, in L. Anselin, R. Florax (eds) New Directions in Spatial Econometrics, Springer, Berlin, 1995, pp. 229-242. 
[12] Dye, R., McGuire, T., McMillen, D., Are property tax limitations more binding over time? National Tax Journal, 58 (2005) 215-225.

[13] Elhorst, P., Applied spatial econometrics: Raising the bar, Spatial Economic Analysis, 5 (2010) 9-28.

[14] Figlio, D., Did the tax revolt reduce school performance? Journal of Public Economics, 65 (1997) 245-269.

[15] Fiva, J., Rattso, J:, Local choice of property taxation: Evidence from Norway, Public Choice 132 (2007) 457-470.

[16] Fleming, M., Techniques for estimating spatially dependent discrete choice models, in L. Anselin, R. Florax and S. Rey (eds), Advances in Spatial Econometrics, Springer, Heidelberg, 2004, pp. 145-168.

[17] Flores-Lagunes, A., Schnier, Estimation of sample selection models with spatial dependence, Journal of Applied Econometrics (2010) forthcoming.

[18] Hautsch, N., Klotz, S., Estimating the neighborhood influence on decision makers: Theory and an application on the analysis of innovation decisions, Journal of Economic Behavior \& Organization, 52 (2003) 97-113.

[19] Jenkins, S., Easy ways to estimate discrete time duration models, Oxford Bulletin of Economics and Statistics, 57 (1995) 129-138.

[20] Joumard, I., Kongsrud, M., Fiscal relations across government levels, OECD Economics Department Working Paper 375 (2003).

[21] Klier, T., McMillen, D., Clustering of auto supplier plants in the US, Journal of Business and Economic Statistics 26 (2008) 460-471.

[22] Konrad, K., Non-binding minimum taxes may foster tax competition, Economics Letters 102 (2009) 109-111.

[23] LeSage, J., Bayesian estimation of limited dependent variable spatial autoregressive models, Geographical Analysis 32 (2000) 19-35. 
[24] LeSage, J., Kelley Pace, R., Introduction to Spatial Econometrics, Taylor and Francis, 2009.

[25] Mahadi, K., Schroeder, L., Wang, H., Provincial motor vehicle taxation in Indonesia, Bulletin of Indonesian Economic Studies 29 (1993) 95-110.

[26] Manski, C., Identification of endogenous social effects: The reflection problem, Review of Economic Studies 60 (1993) 531-542.

[27] Maskin, E., Qian, Y., Xu, C., Incentives, information, and organizational form, Review of Economic Studies 67 (2000) 359-378.

[28] McMillen, D., Probit with spatial autocorrelation, Journal of Regional Science 32 (1992) 335-348.

[29] Nechyba, T., Local property and state income taxes: The role of interjurisdictional competition and collusion, Journal of Political Economy, 105 (1997) 351-384.

[30] Paez, A., Scott, D., Social influence on travel behavior: a simulation example of the decision to telecommute, Environment and Planning A 39 (2007) 647-665.

[31] Paez, A., Scott, D., Volz, E., A discrete-choice approach to modeling social influence on individual decision making, Environment and Planning B 35 (2008) 1055-1069.

[32] Pinkse J., Slade M., Contracting in space: An application of spatial statistics to discrete-choice models, Journal of Econometrics 85 (1998) 125-154.

[33] Pudney, S., Modelling Individual Choice. The Econometrics of Corners, Kinks and Holes. Blackwell, Oxford, 1991.

[34] Revelli, F., On spatial public finance empirics, International Tax and Public Finance 12 (2005) 475-492. 
[35] Revelli, F., Performance competition in local media markets, Journal of Public Economics 92 (2008) 1585-1594.

[36] Solé Ollé, A., Electoral accountability and tax mimicking: The effects of electoral margins, coalition government, and ideology, European Journal of Political Economy 19 (2003) 685-713.

[37] Sutherland, D., Price, R., Joumard, I., Sub-central government fiscal rules, OECD Economic Studies 41 (2005) 141-181.

[38] Suter, S., Walter, F., Environmental pricing: Theory and practice, Journal of Transport Economics and Policy 35 (2001) 381-397.

[39] Vigdor, J., Other people's taxes: Nonresident voters and statewide limitation of local government, Journal of Law and Economics 47 (2004) 453-477.

[40] Wang, Y., Commodity taxes under fiscal competition: Stackelberg equilibrium and optimality, American Economic Review 89 (1999) 974-981.

[41] Wolman, H., McManmon, R., Bell, M., Brunori, D., Comparing local government autonomy across states, Working Paper No. 35/2008, George Washington Institute for Public Policy, Washington.

[42] Zodrow, G., The property tax incidence debate and the mix of state and local finance of local public expenditures, CESifo Economic Studies, 53 (2007) 495-521. 
Table 1 The provincial vehicle registration tax: key statistics

\begin{tabular}{ccccc}
\hline & Average $\tau$ & $\tau_{t}=\underline{\tau}$ & $\tau_{t}=\bar{\tau}$ & $\tau_{t}=\bar{\tau} \mid \tau_{t-1}<\bar{\tau}$ \\
\hline 2000 & 11.9 & 31 & 56 & 56 \\
\hline 2001 & 14.5 & 19 & 68 & 12 \\
\hline 2002 & 16.5 & 9 & 79 & 11 \\
\hline 2003 & 16.7 & 8 & 80 & 1 \\
\hline 2004 & 16.9 & 8 & 81 & 1 \\
\hline 2005 & 17.6 & 6 & 86 & 5 \\
\hline 2006 & 18 & 4 & 88 & 2 \\
\hline \hline $2000-2006$ & 16.5 & & &
\end{tabular}

Notes: 100 Provinces; $\tau$ is the provincial vehicle registration tax rate spread. $\underline{\tau}$ and $\bar{\tau}$ are the lower $(0 \%)$ and upper (20\%) bounds set by central government respectively. 
Table 2 Vehicle tax policy and provincial elections

\begin{tabular}{|c|c|c|c|}
\hline & $e l=1$ & $\overline{\Delta \tau>0}$ & $\Delta \tau>0 \quad \& \quad e l=1$ \\
\hline 2000 & 6 & 69 & 2 \\
\hline 2001 & 9 & 14 & 0 \\
\hline 2002 & 10 & 15 & 1 \\
\hline 2003 & 12 & 2 & 1 \\
\hline 2004 & 63 & 3 & 0 \\
\hline 2005 & 6 & 7 & 0 \\
\hline 2006 & 13 & 3 & 0 \\
\hline $2000-2006$ & 119 & 113 & 4 \\
\hline$\%$ re-elected & 76.5 & & 50 \\
\hline
\end{tabular}

Notes: 100 Provinces; $e l=1$ in year $t$ if a provincial election is held in that year. $\Delta \tau=\tau_{t}-\tau_{t-1}$ is the change in the provincial vehicle registration tax spread $\tau$ from year $t-1$ to year $t$. Setting a positive tax in year 2000 (the year of introduction of the provincial vehicle tax) is treated as a tax increase. 
Table 3 Vehicle tax spread determination: baseline linear specification

\begin{tabular}{|c|c|c|c|c|}
\hline & (a) & (b) & (c) & (d) \\
\hline & $\mathrm{ML}$ & OLS & ML & ML \\
\hline constant & $\begin{array}{c}-4.224^{* * *} \\
(0.373)\end{array}$ & $\begin{array}{c}-3.281^{* * *} \\
(0.464)\end{array}$ & $\begin{array}{c}-3.658^{* * *} \\
(0.429)\end{array}$ & $\begin{array}{c}-4.161^{* * *} \\
(0.422)\end{array}$ \\
\hline$\rho$ & & $\begin{array}{c}0.201^{* * *} \\
(0.060)\end{array}$ & $\begin{array}{c}0.121^{* * *} \\
(0.047)\end{array}$ & \\
\hline$\lambda$ & & & & $\begin{array}{c}0.121^{* * *} \\
(0.047)\end{array}$ \\
\hline Fixed province effects & yes & yes & yes & yes \\
\hline Log likelihood & -1914.49 & & -1911.21 & -1911.21 \\
\hline Observations & 700 & 700 & 700 & 700 \\
\hline $\begin{array}{c}\text { Moran test } \\
(p \text { value })\end{array}$ & $\begin{array}{c}3.358 \\
(0.001)\end{array}$ & & & \\
\hline $\begin{array}{c}\text { LM lag test } \\
(p \text { value })\end{array}$ & $\begin{array}{c}8.628 \\
(0.003)\end{array}$ & & & \\
\hline $\begin{array}{l}\text { LM error test } \\
\quad(p \text { value })\end{array}$ & $\begin{array}{c}8.628 \\
(0.003)\end{array}$ & & & \\
\hline $\begin{array}{l}\text { LR test } \\
(p \text { value })\end{array}$ & & & $\begin{array}{c}6.552 \\
(0.010)\end{array}$ & $\begin{array}{c}6.552 \\
(0.010)\end{array}$ \\
\hline
\end{tabular}

Notes: dep. var. $=$ provincial tax spread $(0 \leq \tau \leq 20)$; standard errors in parentheses; ${ }^{*},{ }^{* *}, * * *(\mathrm{p}-$ value $<0.10,0.05,0.01)$. 
Table 4 Vehicle tax spread determination: full linear specification

\begin{tabular}{|c|c|c|c|c|}
\hline & (e) & $(\mathrm{f})$ & $(\mathrm{g})$ & (h) \\
\hline & $\mathrm{ML}$ & OLS & $\mathrm{ML}$ & $\mathrm{ML}$ \\
\hline constant & $\begin{array}{c}-5.053^{* * *} \\
(0.505)\end{array}$ & $\begin{array}{c}-4.296^{* * *} \\
(0.612)\end{array}$ & $\begin{array}{c}-4.606^{* * *} \\
(0.567)\end{array}$ & $\begin{array}{c}-4.965^{* * *} \\
(0.531)\end{array}$ \\
\hline election dummy $_{i t}$ & $\begin{array}{c}-0.641 \\
(0.443)\end{array}$ & $\begin{array}{c}-0.580 \\
(0.436)\end{array}$ & $\begin{array}{l}-0.605 \\
(0.428)\end{array}$ & $\begin{array}{c}-0.632 \\
(0.447)\end{array}$ \\
\hline grants $_{i t}$ & $\begin{array}{c}-2.966^{* * *} \\
(0.729) \\
\end{array}$ & $\begin{array}{c}-2.630^{* * *} \\
(0.743)\end{array}$ & $\begin{array}{c}-2.769^{* * *} \\
(0.733)\end{array}$ & $\begin{array}{c}-2.790^{* * *} \\
(0.757)\end{array}$ \\
\hline income $_{i t-1}$ & $\begin{array}{c}-0.446^{*} \\
(0.244)\end{array}$ & $\begin{array}{c}-0.417^{*} \\
(0.245)\end{array}$ & $\begin{array}{c}-0.429^{*} \\
(0.247)\end{array}$ & $\begin{array}{l}-0.435^{*} \\
(0.245)\end{array}$ \\
\hline stock of vehicles $i t-1$ & $\begin{array}{l}1.774^{* *} \\
(0.718)\end{array}$ & $\begin{array}{l}1.728 * * \\
(0.714)\end{array}$ & $\begin{array}{l}1.747^{* *} \\
(0.717)\end{array}$ & $\begin{array}{l}1.751^{* *} \\
(0.716)\end{array}$ \\
\hline right-wing dummy ${ }_{i t-1}$ & $\begin{array}{l}-0.575 \\
(0.866)\end{array}$ & $\begin{array}{l}-0.481 \\
(0.826)\end{array}$ & $\begin{array}{l}-0.519 \\
(0.825) \\
\end{array}$ & $\begin{array}{l}-0.502 \\
(0.830)\end{array}$ \\
\hline$\rho$ & & $\begin{array}{c}0.135^{* *} \\
(0.061)\end{array}$ & $\begin{array}{l}0.080^{*} \\
(0.047)\end{array}$ & \\
\hline$\lambda$ & & & & $\begin{array}{c}0.062 \\
(0.048)\end{array}$ \\
\hline Fixed province effects & yes & yes & yes & yes \\
\hline Log likelihood & -1898.87 & & -1897.45 & -1898.08 \\
\hline Observations & 700 & 700 & 700 & 700 \\
\hline $\begin{array}{c}\text { Moran test } \\
(p \text { value })\end{array}$ & $\begin{array}{c}1.882 \\
(0.060)\end{array}$ & & & \\
\hline $\begin{array}{l}\text { LM lag test } \\
(p \text { value })\end{array}$ & $\begin{array}{c}3.690 \\
(0.055) \\
\end{array}$ & & & \\
\hline $\begin{array}{c}\text { LM error test } \\
(p \text { value })\end{array}$ & $\begin{array}{c}2.019 \\
(0.155) \\
\end{array}$ & & & \\
\hline $\begin{array}{l}\text { LR test } \\
(p \text { value })\end{array}$ & & & $\begin{array}{c}2.840 \\
(0.091)\end{array}$ & $\begin{array}{c}1.570 \\
(0.210)\end{array}$ \\
\hline
\end{tabular}

Notes: dep. var. $=$ provincial tax spread $(0 \leq \tau \leq 20)$; standard errors in parentheses; ${ }^{*}, * *,{ }^{* * *}$ (p-value $\left.<0.10,0.05,0.01\right)$; time effects included. 
Table 5 Vehicle tax spread determination: Bayesian model

\begin{tabular}{|c|c|c|}
\hline & (i) & $(\mathrm{j})$ \\
\hline election dummy $_{i t}$ & & $\begin{array}{l}-0.609 \\
(0.810)\end{array}$ \\
\hline grants $_{i t}$ & & $\begin{array}{c}-1.245^{* *} \\
(0.643)\end{array}$ \\
\hline income $_{i t-1}$ & & $\begin{array}{c}0.231^{* * *} \\
(0.056)\end{array}$ \\
\hline stock of vehicles $i t-1$ & & $\begin{array}{c}-0.645^{* * *} \\
(0.064)\end{array}$ \\
\hline right-wing dummy $i t-1$ & & $\begin{array}{c}-2.589^{* * *} \\
(0.599)\end{array}$ \\
\hline$\rho$ & $\begin{array}{c}0.153^{* * *} \\
(0.051)\end{array}$ & $\begin{array}{c}0.098^{* *} \\
(0.050)\end{array}$ \\
\hline year 2001 & $\begin{array}{c}12.132^{* * *} \\
(1.023)\end{array}$ & $\begin{array}{c}12.985^{* * *} \\
(1.510)\end{array}$ \\
\hline year 2002 & $\begin{array}{c}14.231^{* * *} \\
(1.134)\end{array}$ & $\begin{array}{c}15.526^{* * *} \\
(1.609)\end{array}$ \\
\hline year 2003 & $\begin{array}{c}14.443^{* * *} \\
(1.108)\end{array}$ & $\begin{array}{c}15.860^{* * *} \\
(1.625)\end{array}$ \\
\hline year 2004 & $\begin{array}{c}14.575^{* * *} \\
(1.171)\end{array}$ & $\begin{array}{c}16.169^{* * *} \\
(1.669)\end{array}$ \\
\hline year 2005 & $\begin{array}{c}15.242^{* * *} \\
(1.203)\end{array}$ & $\begin{array}{c}16.458^{* * *} \\
(1.596)\end{array}$ \\
\hline year 2006 & $\begin{array}{c}15.626^{* * *} \\
(1.199)\end{array}$ & $\begin{array}{c}16.774^{* * *} \\
(1.585)\end{array}$ \\
\hline Observations & 700 & 700 \\
\hline $\begin{array}{c}\text { Right-censored } \\
\left(\tau_{i t}=\bar{\tau}\right)\end{array}$ & 538 & 538 \\
\hline
\end{tabular}

Notes: standard errors in parentheses; ${ }^{*}, * *, * * *(p$-value $<0.10,0.05,0.01)$. 
Table 6 Vehicle tax spread determination: Tobit and hazard models

\begin{tabular}{|c|c|c|c|}
\hline & $(\mathrm{k})$ & (l) & $(\mathrm{m})$ \\
\hline & \multicolumn{2}{|c|}{ Tobit } & hazard (Probit) \\
\hline \multirow{2}{*}{ election dummy $_{i t}$} & -0.047 & -0.056 & -0.100 \\
\hline & $(0.551)$ & $(0.649)$ & $(0.078)$ \\
\hline \multirow{2}{*}{$\operatorname{grants}_{i t}$} & 0.002 & 0.002 & -0.001 \\
\hline & $(0.005)$ & $(0.005)$ & $(0.001)$ \\
\hline \multirow{2}{*}{ income $_{i t-1}$} & 0.043 & 0.051 & $-0.017^{* * *}$ \\
\hline & $(0.038)$ & $(0.045)$ & $(0.006)$ \\
\hline \multirow{2}{*}{ stock of vehicles $_{i t-1}$} & $-2.335^{* * *}$ & $-2.774^{* * *}$ & -0.030 \\
\hline & $(0.379)$ & $(0.418)$ & $(0.051)$ \\
\hline \multirow{2}{*}{ right-wing dummy $i t-1$} & $-1.864^{* * *}$ & $-2.062^{* * *}$ & $-0.109^{*}$ \\
\hline & $(0.502)$ & $(0.518)$ & $(0.070)$ \\
\hline \multirow{2}{*}{$\frac{\partial E\left(\tau_{i t} \mid x_{i t}, \tau_{-i t-1}\right)}{\partial \tau_{-i t-1}}$} & $0.152^{* * *}$ & & \\
\hline & $(0.047)$ & & \\
\hline \multirow{2}{*}{$\frac{\partial E\left(\tau_{i t} \mid \tau_{i t}<\bar{\tau}, x_{i t}, \tau_{-i t-1}\right)}{\partial \tau_{-i t-1}}$} & & $0.180^{* * *}$ & \\
\hline & & $(0.055)$ & \\
\hline \multirow{2}{*}{$\frac{\partial P\left(\tau_{i t}=\bar{\tau}\right)}{\partial \tau_{-i t-1}}$} & & & $0.015^{* *}$ \\
\hline & & & $(0.007)$ \\
\hline \multirow{2}{*}{ year 2002} & -0.791 & -0.880 & $0.371^{* *}$ \\
\hline & $(0.891)$ & $(0.932)$ & $(0.197)$ \\
\hline \multirow{2}{*}{ year 2003} & 0.130 & 0.157 & $0.438^{* *}$ \\
\hline & $(0.679)$ & $(0.827)$ & $(0.206)$ \\
\hline \multirow{2}{*}{ year 2004} & -0.148 & -0.173 & 0.006 \\
\hline & $(0.719)$ & $(0.832)$ & $(0.178)$ \\
\hline \multirow{2}{*}{ year 2005} & 0.436 & 0.542 & $0.338^{*}$ \\
\hline & $(0.632)$ & $(0.821)$ & $(0.234)$ \\
\hline \multirow{2}{*}{ year 2006} & 0.614 & 0.777 & 0.173 \\
\hline & $(0.599)$ & $(0.811)$ & $(0.237)$ \\
\hline Observations & 600 & 600 & 150 \\
\hline $\begin{array}{c}\text { corner solutions } \\
\quad\left(\tau_{i t}=20\right)\end{array}$ & 482 & 482 & 32 \\
\hline
\end{tabular}

Notes: standard errors in parentheses; ${ }^{*},{ }^{* *}, * * *$ (p-value $\left.<0.10,0.05,0.01\right)$. 


\section{Appendix}

Table A1 Variables used in the analysis: descriptive statistics

\begin{tabular}{lrrrrr}
\hline & obs. & mean & s.d. & min & max \\
\hline \hline \multicolumn{1}{c}{ SPATIAL LAG DEPENDENCE, CENSORED, TOBIT MODELS } & \\
\hline Vehicle tax spread (\%) & 700 & 16.5 & 6.9 & 0 & 20 \\
\hline Stock of vehicles $(, 000)$ & 700 & 426.9 & 486.1 & 57.1 & 3514.2 \\
\hline Newly registered vehicles $(, 000)$ & 700 & 31.4 & 50.5 & 3.1 & 471.2 \\
\hline Income (value added per capita; ,000 €) & 700 & 20.1 & 5.0 & 10.8 & 34.3 \\
\hline Current spending per capita $(€)$ & 700 & 155.4 & 50.8 & 55.6 & 327.3 \\
\hline Grants per capita (€) & 700 & 93.8 & 49.0 & 3.5 & 243.2 \\
\hline Right-wing control $(\%)$ & 700 & 36 & & & \\
\hline \hline & DISCRETE HAZARD MODEL & & & \\
\hline Vehicle tax spread (\%) & 150 & 8.9 & 8.0 & 0 & 20 \\
\hline Stock of vehicles (,000) & 150 & 704.5 & 822.0 & 59.5 & 3383.1 \\
\hline Newly registered vehicles $(, 000)$ & 150 & 56.6 & 86.5 & 3.2 & 414.6 \\
\hline Income (value added per capita;, $000 €)$ & 150 & 19.7 & 6.1 & 10.9 & 34.3 \\
\hline Current spending per capita $(€)$ & 150 & 136.0 & 40.8 & 69.7 & 251.3 \\
\hline Grants per capita (€) & 150 & 79.9 & 44.8 & 11.9 & 196.7 \\
\hline Right-wing control (\%) & 150 & 55 & & & \\
\hline
\end{tabular}

Table A2 Variables used in the analysis: data sources

\begin{tabular}{lcc}
\hline & SOURCE & YEARS \\
\hline Vehicle tax & Automobile Club Italy - Quattroruote & $2000-2006$ \\
\hline Stock of vehicles & Public Registry of Vehicles & $1999-2006$ \\
\hline Vehicle registrations & Public Registry of Vehicles & $1999-2006$ \\
\hline Income & National Statistics Institute & $1999-2005$ \\
\hline Current spending & Italian Government, Home Office & $2000-2006$ \\
\hline Grants & Italian Government, Home Office & $2000-2006$ \\
\hline Right-wing control & Italian Government, Home Office & $1999-2006$ \\
\hline
\end{tabular}



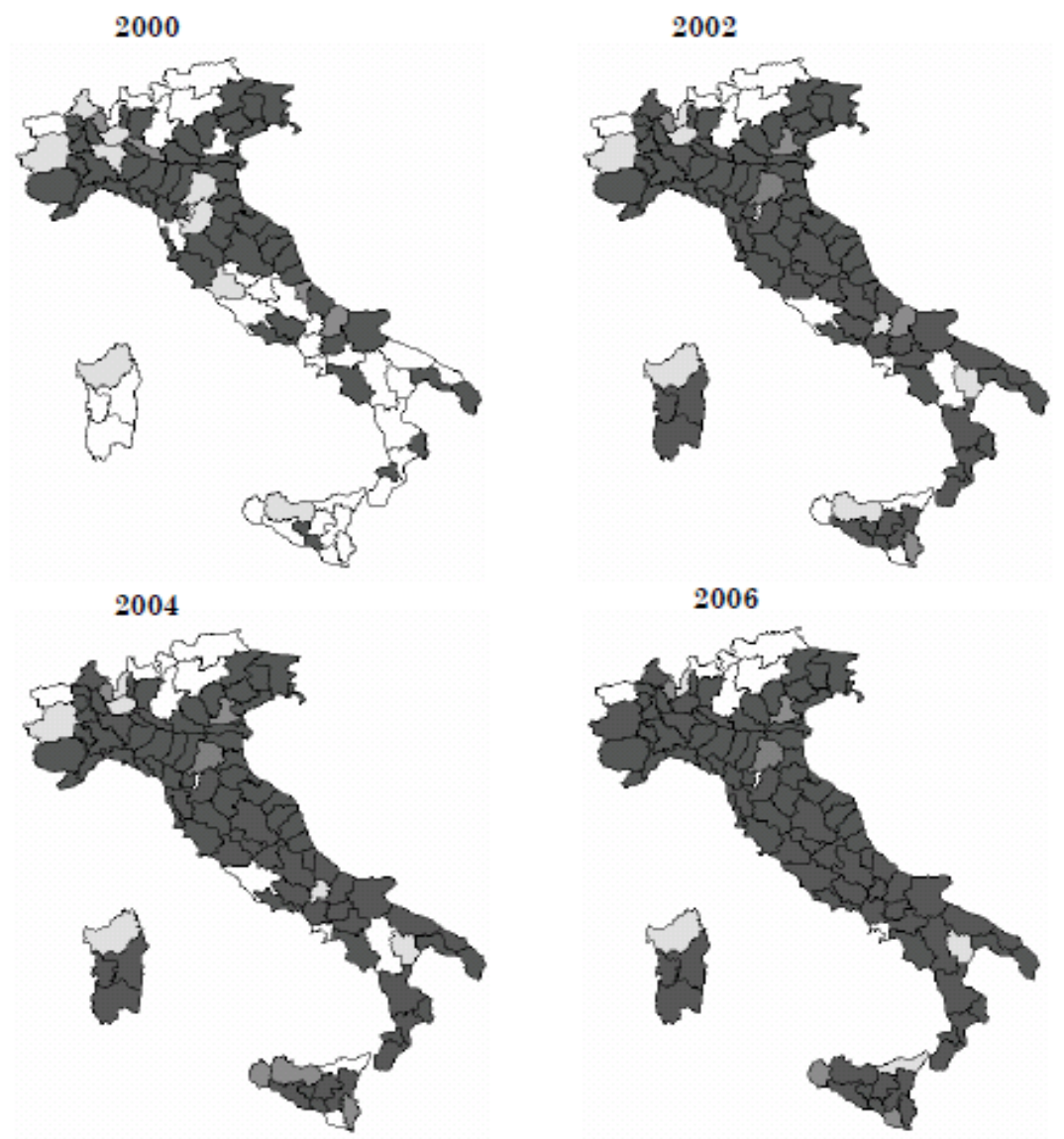

Notes:

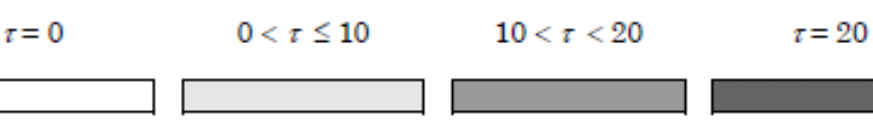

Figure 1: Vehicle tax spatial pattern 